\title{
Energy storage system for global maximum power point tracking on central inverter PV plants
}

\begin{abstract}
Central inverters are the most common configuration for large-scale photovoltaic systems. Under partial shading or any nonuniform conditions on the photovoltaic plant, several power maxima may arise. Conventional perturb and observe and other classical maximum power point tracking algorithms are capable of tracking a local maximum, but can not guarantee to operate at the global maximum. A solution to such limitation is to perform a scan of the photovoltaic characteristic periodically in order to ensure operation at the global maximum. However, such a scan generates high output power variations that may not comply with grid codes. In order to overcome this drawback and allow a global scan for maximum power point tracking purposes, this paper proposes a hybrid photovoltaic system with an ultra-capacitor based energy storage system. Simulations are provide to validated the proposed configuration. Results show that the photovoltaic scan allows operation at the global maximum power point, while the ultra-capacitor manage the power transient so that the output fluctuation are kept within reasonable limits.
\end{abstract}

\section{INTRODUCTION}

In large-scale photovoltaic (PV) system ( $>850 \mathrm{~kW}$ [1]), the central inverter is the most common configuration [1]. Compared with the other existing PV power architecture (string, multi-string and microinverter), the central configuration has the advantage of a lower cost per produced $W$, and a higher conversion efficiency up to $98 \%$ CEC efficiency in commercial products. However, since the central configuration is the less distributed, the maximum power point tracking efficiency is the lowest [1]. Indeed, central inverters perform a single MPPT at the plant level, therefore can be highly affected by partial shading phenomenons.

Under non-uniform conditions, the PV characteristic can have several local maxima. In order to optimize the produced energy, it is mandatory to implement a MPPT algorithm able to track the global maximum. Since classical algorithms such as $\mathrm{P} \& \mathrm{O}$ may remain in a local maximum, it is necessary to implement dedicated methods. One of the simplest solutions is to perform a scan of the PV characteristic, and then start a classical MPPT method around the global MPP as done in [2]-[5]. The scanning process can be performed by modifying the PV voltage reference as detailed in [6]. Another solution consists on adding a dedicated external circuit as in [7], where two methods for obtaining the power-voltage of the PV source are presented.

One of the main drawbacks of scanning is that the system suffers from large power variations, moreover energy loss is necessary to locate the global maximum. Recent work on global MPPT algorithms focuses on reducing those aspects. In [8], the global MPP is known by the use of distributed PV voltage sensors among the modules of the array. It results in higher cost and possible failure but avoid much energy loss due to blind scan. In [9] a scan is performed, but the voltage window search range is restricted not to go from open-circuit voltage to short-circuit. In [10], it is proposed a process which allows reducing the PV array power perturbation steps. More complex algorithms can also be used to find the global maximum. For example in [11], it is proposed a PSO algorithm to reach the global MPP. 
All the mentioned PV curve scan methods suffer from wide variations in the array power which might be prohibited. Indeed, limitation of the PV power variability recently appeared in the regulations [12]. The first country to impose this limitation was Puerto Rico, setting the maximum allowable power variation to $10 \%$ of the nominal power per minute [12]. That limitation comes from the fact that the PV power fluctuation can affect the power quality and reliability of the system, power fluctuations shorter than 10 min being typically absorbed by the grid as frequency fluctuations. This issue is of special importance especially in small grids, such as islands with high PV penetration rates, because the smoothing effect from the aggregation of geographically dispersed PV plants is intrinsically limited, therefore justifying those constraints [12], [13]. In this work, a maximum allowable power fluctuation up

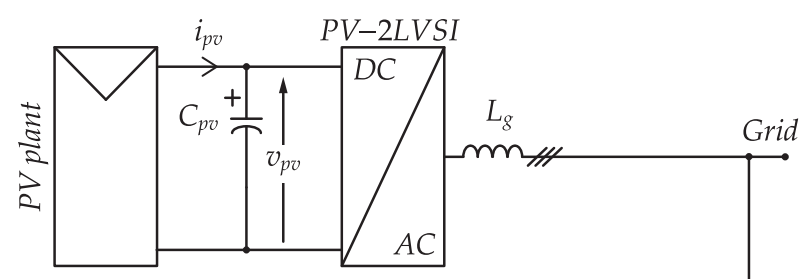

to $10 \%$ of the (nominal) power is considered.

In order to enable the search of the global MPP through a scan of the PV curve, and by the same time meet power fluctuation limitations, the hybridization of the PV central inverter with a storage element is proposed in this paper and is developed as follows. Section II describes the proposed hybrid system. The MPPT control of the PV plant and the energy management are discussed, and the storage element sizing is detailed. Simulation results are provided in section IV in order to validate the behavior of the proposed hybrid system. Finally section V gives the conclusions of this work.

\section{SYSTEM DESCRIPTION AND MODELLING}

A PV system formed by a PV plant and a central inverter configuration is considered, as shown in Fig. 1. For simplicity, a two level voltage source inverter (2LVSI) is chosen as the central inverter topology.

The required storage capability is provided by an ultra-capacitor bank (UC). In order to interface the UC to the grid, a two stage configuration is used. The first stage is formed by an interleaved bidirectional full-bridge (FB) DC/DC converters. The FB converter model and its detailed modulation scheme will be given the final paper. The second stage is composed of a conventional DC/AC 2LVSI.

The PV plant is designed considering Canadian Solar CS6X-325P-FG high isolation PV modules (1.5 kV) [14]. GE ProSolar PSC-800 MV-L-QC central solar inverter [15] is selected as guide line for both 2LVSI parameters. A $320 \mathrm{~V}$ UC bank is used as energy storage element. Sizing of the UC is describes in subsection III-A. Table I shows parameters of the considered system.

III. CONTROL 
TABLE I: Configuration parameters.

\begin{tabular}{|c|c|c|}
\hline \multicolumn{3}{|c|}{ PV power plant (under STC conditions) } \\
\hline Maximum power & $P_{p v m p p}$ & $778 \mathrm{~kW}$ \\
\hline Open circuit voltage & $v_{p v o c v}$ & $1460 \mathrm{~V}$ \\
\hline Short circuit current & $i_{p v s c}$ & $710 A$ \\
\hline Maximum power point voltage & $v_{p v m p p}$ & $1184 \mathrm{~V}$ \\
\hline Maximum power point current & $i_{p v m p p}$ & $657 A$ \\
\hline Modules connected in series & $N_{s m}$ & 36 \\
\hline Strings connected in parallel & $N_{p s}$ & 76 \\
\hline \multicolumn{3}{|c|}{ 2LVSI \& Grid } \\
\hline PV 2LVSI dc-link capacitance & $C_{p v}$ & $4400 \mu F$ \\
\hline UC 2LVSI dc-link capacitance & $C_{o}$ & $4400 \mu F$ \\
\hline PV inverter dc-link voltage & $v_{p v}$ & $720-1500 \mathrm{~V}$ \\
\hline UC inverter dc-link voltage & $v_{o}$ & $1100 \mathrm{~V}$ \\
\hline Grid voltage & $v_{a c R M S}$ & $440 V_{L L} R M S$ \\
\hline Grid inductance & $L_{g}$ & $0.25 \mathrm{mH}$ \\
\hline Grid frequency & $f_{g}$ & $50 \mathrm{~Hz}$ \\
\hline Switching frequency & $f_{s w}$ & $5 \mathrm{kHz}$ \\
\hline \multicolumn{3}{|c|}{$\mathrm{UC} \& \mathrm{FB}$ converter } \\
\hline Capacitance & $C_{u c}$ & $2.9 F$ \\
\hline Maximum voltage & $v_{u c \max }$ & $320 \mathrm{~V}$ \\
\hline FB inductance & $L_{b b}$ & $0.1 \mathrm{mH}$ \\
\hline Isolating transformer ratio & $n_{1}: n_{2}$ & $1: 1$ \\
\hline Switching frequency & $f_{b b}$ & $50 \mathrm{kHz}$ \\
\hline Sampling period & $T_{s}$ & $5 \mu s$ \\
\hline
\end{tabular}

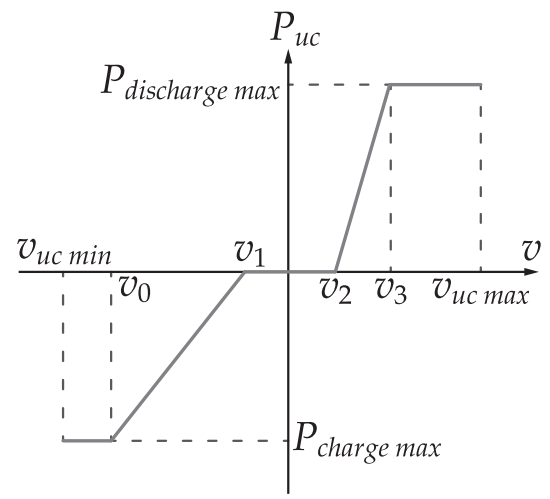

Fig. 2: Charging state UC power reference.

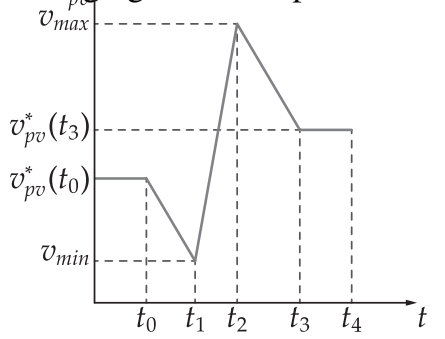

Fig. 3: PV voltage reference for the scanning process of the global MPPT.
PV plant system has a conventional Voltage Oriented Control (VOC), as shown in Fig. 4a. The dc-link voltage reference $\left(v_{p v}^{*}\right)$ is given by a MPPT algorithm, which is described in subsection III-A. In VOC scheme q-axis current reference is set to zero, to generate unitary power factor.

The UC-2LVSI has only the inner current loop of a VOC scheme. The d-axis current reference $\left(i_{g d}^{*}\right)$ is proportional to a power reference $P$, as seen in Fig. $4 \mathrm{~b}, i_{g d}^{*}=k \cdot P$ where $k=2 /\left(3 \cdot v_{g d}\right)$, where $v_{g d}$ is the d-axis grid current. The power reference $P$, corresponds to $P_{u c}-\overline{P_{p v}}+P_{p v}$, where $\overline{P_{p v}}, P_{p v}$ are respectively the average and instantaneous PV plant power. $P_{u c}$ is generated through an external loop, described in section III-A; which depends upon the state of MPPT algorithm. The qaxis current reference $\left(i_{g q}^{*}\right)$, proportional to the reactive power, is set to zero. Dc-link voltage $\left(v_{o}\right)$ control if performed by the FB converter control scheme.

Control strategy for FB converters is shown in Fig. 4c. The external PI controller manages the dc-link voltage $\left(v_{o}\right)$, generating the current reference $\left(i_{L B B x}^{*}, x=\{1,2\}\right)$ for both FB. Since each FB converter handles half the UC current, the reference is divided by $2(n=1 / 2)$. The inner loop manages the current trough both inductors $\left(L_{b b}\right)$, generating the modulation index $\tilde{m}$. The modulation index is limited to operate on a $0-0.5$ range. 


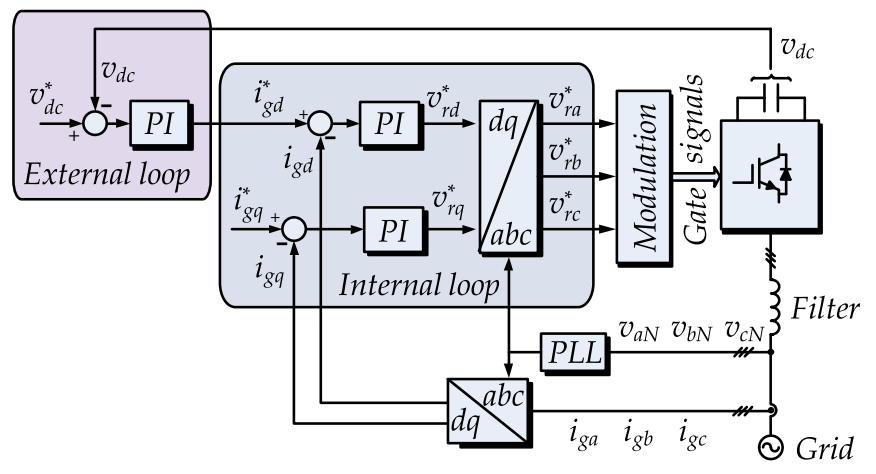

(a) PV plant 2LVSI control scheme.

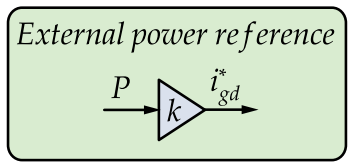

(b) External UC-2LVSI reference.

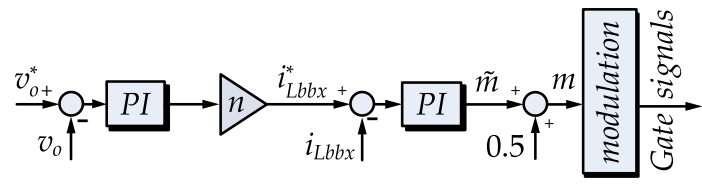

(c) Full bridge control scheme.

Fig. 4: Control schemes.

Afterwards the modulation index is fitted to generate a symmetric voltage wave form in the transformer. FB PWM carriers operate with $\pi / 4 \mathrm{rad} / \mathrm{s}$ phase shift, in order to reduce voltage ripple on the UC.

\section{A. Global MPPS algorithm}

In [9] it is proposed to reduce the voltage range for the scanning part of the global MPPT search, hence reducing the energy lost during this process. It is shown in [9] that the search range can be limited to $\left[v_{\min }, v_{m a x}\right]$ with $v_{p v}$ min $=P_{m p p_{k-1}} / i_{p v} s c_{s t c}$ and $v_{p v \max }=0.9 \cdot v_{p c o c v}$.

Implemented MPPT algorithm has two operating states, PV characteristic scan and standard P\&O [16]. Scanning is performed when a certain time elapses since the last scanning execution (for slow power variations), or if the PV plant output power has a time variation greater than a certain value (for fast power variations). Fig. 3 shows the global maximum power point scan, where $v_{p v}$ is variated from $v_{p v}^{*}\left(t_{0}\right)$ to $v_{p v}^{*}\left(t_{3}\right)$. The voltage scan allows to find the voltage $v_{p v}$ generating the maximum power. After full scanning, maximum power matching voltage is selected as new voltage reference.

In order to size the UC bank, a scan on the PV curve is considered, while the hole plant is kept operating under STC conditions. The dc-link voltage swapping $v_{p v}$ generates a PV plant output power variation. The difference between the average PV plant output power prior to the scanning and the PV plant output power during the scan is calculated and integrated. The result correspond to the energy loss during the scanning process $\left(E_{\text {loss }} \mathrm{kWh}=20 \mathrm{Wh}\right.$ ), this corresponds to $0.0027 \%$ of the total PV plant power generated in an hour $\left(E_{p v k W h}=750 \mathrm{kWh}\right)$. The required energy storage element is chosen to have a voltage range from 300 to $100 \mathrm{~V}$ and a capacity of $C_{u c}=2.9 \mathrm{~F}$, providing an energy storage capacity of $32 \mathrm{Wh}$.

\section{Simulation Results}

Two scans are performed, the first one is time triggered (at $t=0.1 \mathrm{~s}$ ) and a second one is triggered by a solar irradiation change (at $t=2 \mathrm{~s}$ ). Fig 5a shows the PV plant 2LVSI waveforms, in order to perform the scan, the voltaje is swapped as previously described. Once the scanning ends the new voltage value $\left(v_{p v}^{*}\right)$ is set as reference and the system returns to $\mathrm{P} \& \mathrm{O}$ strategy. $\mathrm{P} \& \mathrm{O}$ classic voltaje steps are visible when the system is not performing the scanning procedure.

The behavior of the UC 2LVSI is shown in fig. 5c. The top graphic shows the output powers of the PV plant, energy storage configuration and the overall output power. The dc-link voltaje $v_{o}$ is controlled by the FB converter. The currents in the $\mathrm{d}$ and $\mathrm{q}$ axes are proportional to the active and reactive powers, respectively. Reactive power reference is set to zero. The active 

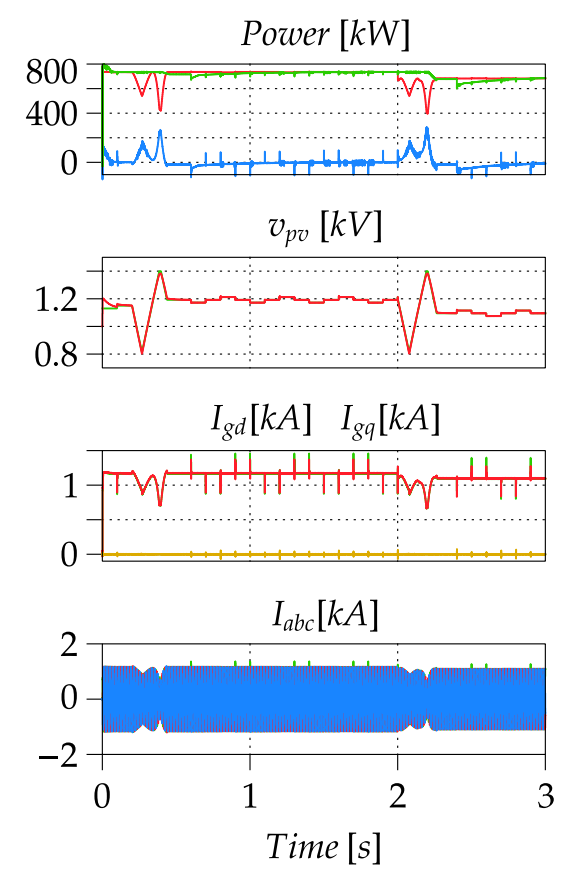

(a) PV plant and PV-2LVSI.

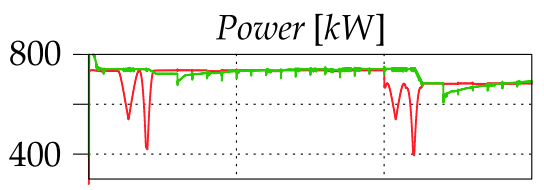

$v_{o}[k V]$
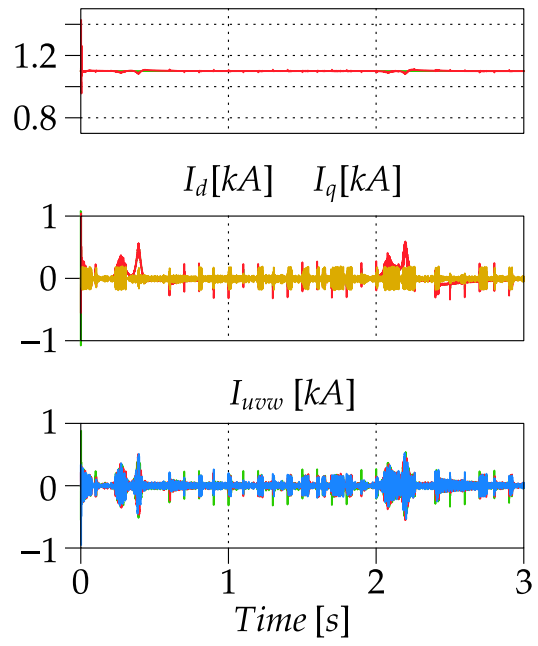

(b) UC-2LVSI.

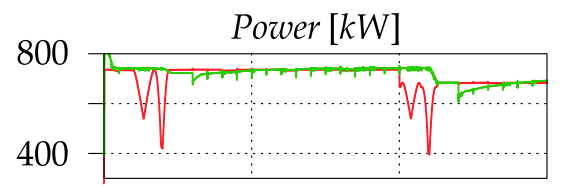

$v_{0}[k V]$
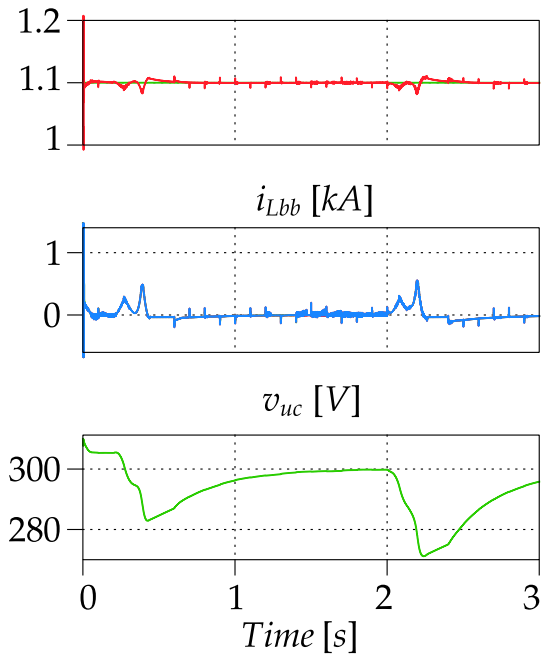

(c) UC and FB converter.

Fig. 5: Simulation results.

power reference $(P)$ has two states, scanning and $\mathrm{P} \& O$. During scanning the power reference is calculated as the difference between the PV plant average power $\left(P_{a v g}\right)$, calculated during the P\&O period, and the current PV power $\left(P_{p v}\right)$. During P\&O the power reference is calculated through the $v_{u c}$ vs $P$ curve, shown in Fig. 2. Line currents and d-axis current reflect the power reference $P$.

FB converter and UC waveforms are displayed in fig 5c. On the top graphic both, PV-2LVSI and total system output power are shown. The total system output power variation does not exceed the $10 \%$ nominal power $(75 \mathrm{~W})$, despite the power variation of the PV output power. Further details will be given in the final version of the paper.

UC-2LVSI dc-link voltaje reference $v_{o}^{*}$ is kept constant at $1100 \mathrm{~V}, v_{o}$ is regulated through the management of both FB converter inductance currents $\left(i_{L b b 1}\right.$ and $\left.i_{L b b 2}\right)$. The voltage on the UC $v_{u c}$, depends upon the MPPT state. When performing scan, energy will be drawn from the UC, hence reducing its voltage, on the other hand when $\mathrm{P} \& \mathrm{O}$ acts, energy is injected from the grid towards the dc-link $C_{o}$ and afterwards to the UC. Since power provided by the UC bank has a small time duration $(0.1 \mathrm{~s})$, the UC-2LVSI may be derated.

\section{CONCLusion}

This paper presents a large-scale central inverter PV plant, hybridized with an UC bank. The additional energy storage capability allow a PV plant with central inverter configuration to perform a global maximum power point tracking, repecting power limitation imposed by legislation at $10 \%$ of the nominal power per minute. The additional energy storage capability can also be used to provide other ancillary services, this matter being the scope of a future work. The proposed system has been presented considering a single central PV inverter. Still, the proposed hybrid system can be though at larger scale, employing a single ultra-capacitor power system at the plant level with various central PV inverters performing the scanning sequentially, then reducing the additional cost. 


\section{REFERENCES}

[1] S. Kouro, J. Leon, D. Vinnikov, and L. Franquelo, "Grid-connected photovoltaic systems: An overview of recent research and emerging pv converter technology," IEEE Ind. Electron. Mag., vol. 9, no. 1, pp. 47-61, March 2015.

[2] H. Renaudineau, A. Houari, J.-P. Martin, S. Pierfederici, F. Meibody-Tabar, and B. Gerardin, "A new approach in tracking maximum power under partially shaded conditions with consideration of converter losses," Solar Energy, vol. 85, pp. 2580-2588, 2011.

[3] Q. Duan, J. Leng, P. Duan, B. Hu, and M. Mao, "An improved variable step po and global scanning mppt method for pv systems under partial shading condition," in Intelligent Human-Machine Systems and Cybernetics (IHMSC), 2015 7th International Conference on, vol. 1, Aug 2015, pp. 382-386.

[4] B. N. Alajmi, K. H. Ahmed, S. J. Finney, and B. W. Williams, "A maximum power point tracking technique for partially shaded photovoltaic systems in microgrids," IEEE Transactions on Industrial Electronics, vol. 60, no. 4, pp. 1596-1606, April 2013.

[5] K. Itako, "Pcs with scanning-type mppt control for industrial grid-connected pv power generation system," in 2014 International Power Electronics Conference (IPEC-Hiroshima 2014 - ECCE ASIA), May 2014, pp. 3244-3248.

[6] H. Renaudineau, F. Donatantonio, J. Fontchastagner, G. Petrone, G. Spagnuolo, J.-P. Martin, and S. Pierfederici, "A pso-based global mppt technique for distributed pv power generation," IEEE Trans. Ind. Electron., vol. 62, no. 2, pp. 1047-1058, Feb 2015.

[7] R. Kot, S. Stynski, and M. Malinowski, "Simple scanning methods for a global-mpp determination in a pv string," in Selected Problems of Electrical Engineering and Electronics (WZEE), 2015, Sept 2015, pp. 1-6.

[8] K. Chen, S. Tian, Y. Cheng, and L. Bai, “An improved mppt controller for photovoltaic system under partial shading condition," IEEE Transactions on Sustainable Energy, vol. 5, no. 3, pp. 978-985, July 2014.

[9] M. Boztepe, F. Guinjoan, G. Velasco-Quesada, S. Silvestre, A. Chouder, and E. Karatepe, "Global mppt scheme for photovoltaic string inverters based on restricted voltage window search algorithm," IEEE Transactions on Industrial Electronics, vol. 61, no. 7, pp. 3302-3312, July 2014.

[10] E. Koutroulis and F. Blaabjerg, "A new technique for tracking the global maximum power point of pv arrays operating under partial-shading conditions," IEEE Journal of Photovoltaics, vol. 2, no. 2, pp. 184-190, April 2012.

[11] K. Ishaque and Z. Salam, "A deterministic particle swarm optimization maximum power point tracker for photovoltaic system under partial shading condition," IEEE Transactions on Industrial Electronics, vol. 60, no. 8, pp. 3195-3206, Aug 2013.

[12] J. Marcos, O. Storkl, L. Marroyo, M. Garcia, and E. Lorenzo, "Storage requirements for $\{$ PV $\}$ power ramp-rate control," Solar Energy, vol. 99, pp. 28 - 35, 2014. [Online]. Available: http://www.sciencedirect.com/science/article/pii/S0038092X13004672

[13] National Renewable Energy Laboratory (NREL). (2013) Review of PREPA Technical Requirements for Interconnecting Wind and Solar Generation. [Online]. Available: www.nrel.gov/docs/fy14osti/57089.pdf

[14] Canadian Solar. (2016) Canadian Solar, solar panels, CS6X-P-FG. [Online]. Available: www.canadiansolar.com

[15] GE power conversion. (2012) GE power conversion, ProSolar Central Solar Inverter. [Online]. Available: www.gepowerconversion.com

[16] P. Bhatnagar and R. Nema, "Maximum power point tracking control techniques: State-of-the-art in photovoltaic applications," Renewable and Sustainable Energy Reviews, vol. 23, pp. 224-241, 2013. 